\title{
Research Article \\ Bolt Pull-Out Tests of Anchorage Body under Different Loading Rates
}

\author{
Tong-bin Zhao, ${ }^{1,2,3}$ Wei-yao Guo, ${ }^{1,3}$ Yan-chun Yin, ${ }^{1,3}$ and Yun-liang Tan ${ }^{1,3}$ \\ ${ }^{1}$ State Key Laboratory of Mining Disaster Prevention and Control Co-Founded by Shandong Province and the Ministry of Science and \\ Technology, Shandong University of Science and Technology, Qingdao 266590, China \\ ${ }^{2}$ State Key Laboratory of Safe and Effective Coal Mining, Anhui University of Science and Technology, Huainan 232001, China \\ ${ }^{3}$ School of Mining and Safety Engineering, Shandong University of Science and Technology, Qingdao 266590, China
}

Correspondence should be addressed to Wei-yao Guo; 363216782@qq.com

Received 13 November 2014; Accepted 9 January 2015

Academic Editor: Shimin Liu

Copyright (C) 2015 Tong-bin Zhao et al. This is an open access article distributed under the Creative Commons Attribution License, which permits unrestricted use, distribution, and reproduction in any medium, provided the original work is properly cited.

Based on the force analysis and mechanical transmission mechanism of grouting bolts, the self-developed test apparatus for interfacial mechanics is used to study the distribution rule of axial force and interfacial stress of bolts in anchorage body. At the same time, pull-out tests of anchorage body are simulated with the particle flow code software $\left(\mathrm{PFC}^{2 \mathrm{D}}\right)$, and stress distribution and failure patters are researched under different loading rates. The results show that the distribution of axial force and interfacial shear stress is nonuniform along the anchorage section: axial force decreases, shear force increases first and then decreases, and the maximum value of both of them is closed to the pull-out side; with the increase of loading rates, both of axial force and interfacial shear stress show a trend of increase in the upper anchorage section but changes are not obvious in the lower anchorage section, which causes serious stress concentration; failure strength of pull-out and loading rates show a linear correlation; according to loading rates' impact on the anchoring effect, the loading rates' scope can be divided into soft scope $(v<10 \mathrm{~mm} / \mathrm{s})$, moderate scope $(10 \mathrm{~mm} / \mathrm{s}<v<100 \mathrm{~mm} / \mathrm{s})$, and strong scope $(v>100 \mathrm{~mm} / \mathrm{s})$.

\section{Introduction}

Rock burst is a special form of mine pressure. It is a dynamic failure phenomenon due to the instantaneous release of energy caused by the accumulated energy that exceeds the strength of coal and rock under high stress of surrounding rock of roadways or working faces, and it can bring serious threats to the safety production of coal mines [1-3]. In order to reduce the damage caused by rock burst, international academics have done a deep study in the field of rock burst, such as occurrence mechanism $[4,5]$, monitoring $[6,7]$, and control technique $[8,9]$. What is more, new technique of roadway support and design have been put forward, such as support technique of rigid and flexible energy storage [10], the high pretension and intensive bolts with U-shaped steel [11], and large deformation bolt cable [12]. These support methods effectively reduce the harm of rock burst. All of these support techniques contain bolt support which is an essential part.
Therefore, the study of anchorage mechanism of bolts under shock load has an important role in the design of roadway support.

Bolt supporting technology is an effective reinforcement technique for roadway surrounding rock, and it has been widely used in coalmine production $[13,14]$. The research of interaction between bolts surrounding rock and anchorage mechanism is essential for the effectiveness of the anchorage design and the stable control of roadway surrounding rock. Many international scholars did lots of research work in this area [15-17]. Lots of field tests and laboratory tests show that the failure of anchorage body mostly appears in the bonding interface, so the distribution of interfacial shear stress is one of the focuses for researching the anchorage mechanism. There are three main ideas about the distribution pattern of interfacial shear stress: power function theory [18], "neutral point" theory [19], and shear stress distribution based on Mindlin solution [20]. The results above have been got 


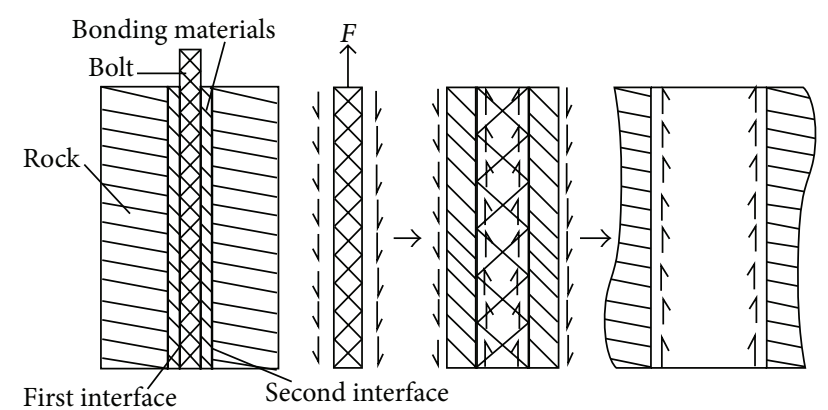

FIGURE 1: The structure of anchorage body and its stress distribution.

through the analysis of bolts under static load, but in mines of rock burst, bolts of roadway surrounding rock are often pulled out fast and then lead to anchorage failure. Therefore, the research of mechanical behaviors of anchorage structure under different loading rates is of importance to guide the rock-burst roadway support. In this paper, the test apparatus for interfacial mechanics based on self-development is used to study the distribution rule of axial force and interfacial shear stress of the anchorage structure. Using the $\mathrm{PFC}^{2 \mathrm{D}}$ software, bolt drawing tests are simulated to study the stress distribution characteristics of anchorage structure under different loading rates and analyze the failure patterns of anchorage body.

\section{Testing Theory for Interfacial Stress of Anchorage Structure}

In the bolt supporting system of roadways, under the influence of deformation and stress of surrounding rock, bolt plates move and deform with the rock mass's surface. At the same time, the plate pulls the bolt, which makes the bolt in tension. The analysis of the bolt's mechanics characteristics and its relationship with the surrounding rock under pull-out condition is significant for the research of anchorage support and anchorage mechanism.

The bolt and anchoring rock mass in the roadway's surrounding rock can be called anchorage body, which is composed of three mediums (bolt, bonding materials, and rock mass) and two bonding interfaces (the first interface: the contact area between bolts and bonding material; the second interface: the contact area between rock mass and bonding materials) [21], as is shown in Figure 1. When the bolt is pulled, the transmission of force is from the bolt body to bonding materials and then to rock mass. Therefore, the research of stress distribution of the surface is the premise and foundation for establishing anchorage design and theory.

During the test, the end of the bolt is exerted by a force $F$, under the action of the external force; the bolt body bar will produce a tensile mechanical response. The bolt body is pulled, which will produce shear mechanical effects between bolts and bonding materials, and its mechanical model is shown in Figure 2 [21]. The corresponding points' axial force can be calculated by the strain value of the bolt body:

$$
N_{i}=E \varepsilon_{i} A,
$$

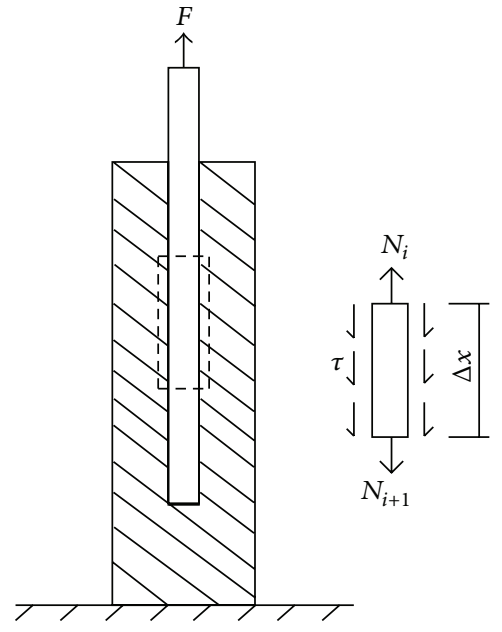

FIGURE 2: Interfacial mechanics model between bolts and bonding materials.

where $N_{i}$ is the axial force of the strain gauge of point $i, E$ is the elastic modulus of the steel bolt body, $\varepsilon_{i}$ is the strain value of point $i$, and $A$ is the area of cross section of the steel bolt body.

The analysis of bolt body's balance conditions is shown in Figure 2, where the axial force difference between two ends of the bolt body is balanced by the longitudinal shear stress in the surface and this kind of shear stress is bonding stress provided by bonding materials around. The axial shear stress distribution along the bolt can be got through formulas (2). From the equilibrium relation, we can get

$$
\begin{gathered}
N_{i}-N_{i+1}=\tau_{i, i+1} \pi d \Delta x, \\
\tau_{i, i+1}=\frac{N_{i}-N_{i+1}}{\pi d \Delta x},
\end{gathered}
$$

where $\tau_{i, i+1}$ is the average interfacial shear stress between points $i$ and point $i+1, d$ is the diameter of the bolt body, and $\Delta x$ is distance between strain gauges.

\section{Pull-Out Test Method}

3.1. Development of Indoor Test Apparatus. The test apparatus for interfacial mechanics is based on RLJW-2000 servo testing machine, using the original hardware facilities and control system, and so forth, and through specific technical means (changing the oil-way, increasing the number of acquisition systems, making the anchorage body, and designing connective device) to achieve pull-out tests of anchorage body. The test apparatus for interfacial mechanics is shown in Figure 3; the connective device between each component is mainly connected by screws. The end of anchorage body is connected with the oil cylinder of the test through eye nuts, knuckle bearing, and junction plate, and the other end of the anchorage body is connected with the bearing-pull board through screws.

The anchorage body mainly includes the bolt, the matrix, and bonding materials, as is shown in Figure 4. The anchorage matrix is concrete materials, and three steel bars are 
TABLE 1: Micromechanical parameters of anchorage body's pull-out test.

\begin{tabular}{lcccccc}
\hline Properties & $\begin{array}{c}\text { Density } \\
\left(\mathrm{kg} / \mathrm{m}^{3}\right)\end{array}$ & $\begin{array}{c}\text { Radius } \\
(\mathrm{mm})\end{array}$ & Friction coefficient & $\begin{array}{c}\text { Radius of parallel } \\
\text { bond }(\mathrm{mm})\end{array}$ & $\begin{array}{c}\text { Elasticity modulus } \\
(\mathrm{GPa})\end{array}$ & $\begin{array}{c}\text { Bonding strength } \\
(\mathrm{MPa})\end{array}$ \\
\hline Bolt & 7500 & 10 & 0.5 & 1 & 220 & 500 \\
Bonding materials & 3000 & $1.3 \sim 1.7$ & 0.5 & 1 & 12 & 30 \\
Matrix & 2500 & $1.3 \sim 1.7$ & 0.5 & 1 & 10 & 20 \\
\hline
\end{tabular}

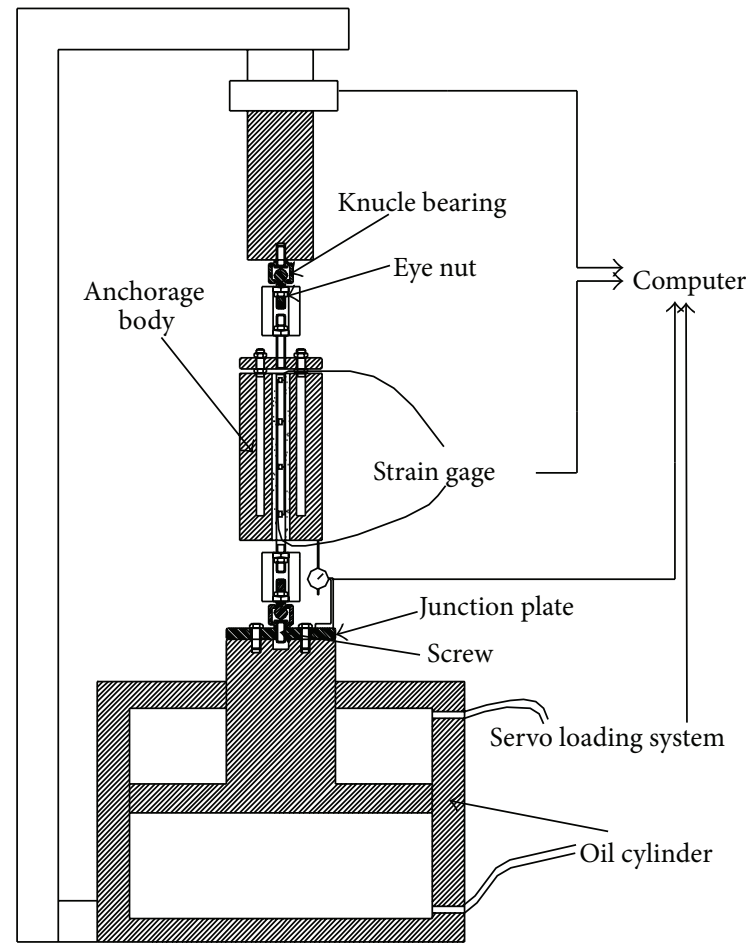

FIGURE 3: Pull-out test apparatus of anchorage body.

embedded in the concrete column for fixing the matrix when testing. The bolt is screw-thread steel, two symmetric cuttings are designed in the bolt anchorage section, and strain gauges are arranged in cuttings. The force bolt is inserted into the concrete matrix with resin to bond them.

The alternated RLJW-2000 testing machine is loading system for pull-out tests of the anchorage body, the DH3815N strain gauge is stress testing system for interfacial stress, and dial indicators are used to record pulling displacement of the bolt end. The loading rate is $5 \mathrm{~mm} / \mathrm{min}$.

3.2. Numerical Tests of Particle Flow. Preparations of the anchorage body are complex, mechanical properties between anchorage models are discrete, and the machine's loading rate fluctuates in a limited range, so dynamic loading tests cannot be carried out, although laboratory pull-out tests of anchorage body are effective means for studying the interfacial mechanics characteristics. Therefore, $\mathrm{PFC}^{2 \mathrm{D}}$ software is used to establish a pull-out test model of the anchorage body (the basic numerical model's establishment was based on the laboratory tests' results), and then numerical tests are used to research the anchorage mechanical characteristics under different loading rates.

The $\mathrm{PFC}^{2 \mathrm{D}}$ is used as the numerical software, which is an effective means for the study of rock and soil mechanical failure mechanism [22]. The parallel bond model in the particle flow program represents the bonding between particles, which is often used to simulate dense materials, such as rock. Parameters in the parallel bond model which need to be set are grain friction coefficient $(\mu)$, bond stiffness $\left(k_{n}\right.$ and $\left.k_{s}\right)$, parallel bond stiffness $\left(\bar{k}_{n}\right.$ and $\left.\bar{k}_{s}\right)$, parallel bond strength $\left(\sigma_{n}\right.$ and $\sigma_{s}$ ), and radius coefficient of parallel bond $(\lambda)$. These parameters can be obtained from the following [23]:

$$
\begin{gathered}
k_{n}=2 E_{c}, \\
k_{s}=\frac{k_{n}}{k_{n} / k_{s}}, \\
\bar{k}_{n}=\frac{\bar{E}_{c}}{2 \bar{r}}, \\
\bar{k}_{s}=\frac{\bar{k}_{n}}{\bar{k}_{n} / \bar{k}_{s}},
\end{gathered}
$$

where $E_{c}$ and $\bar{E}_{c}$ are Young's modulus of grain contact and parallel grain contact, respectively; both $\left(k_{n} / k_{s}\right)$ and $\left(\bar{k}_{n} / \bar{k}_{s}\right)$ are set to be 2.5 generally; $\bar{r}$ is the mean radius between two grains; $\lambda$ is often set to be 1 . Generally, $E_{c}$ and $\bar{E}_{c}$ are equal, $\sigma_{n}$ and $\sigma_{s}$ are equal, and the four parameters can be obtained by the method of micromechanical parameters calibration.

In this paper, the parallel bond model to simulate the bolt pull-out test is used and the basic model is shown in Figure 5. The model size is $300 \times 300 \mathrm{~mm}$; the bolt is composed of particles of the same radius, recording the vertical force of bolt particles as bolt axial force during the operating process. Measuring circles are arranged in the bonding materials for recording the interfacial shear stress. Micromechanical parameters are listed in Table 1.

3.3. Testing Scheme. According to strain rates, deformation can be divided into five degrees [24], which is shown in Table 2. In order to quantify different loading rates' effects on the anchorage body, static load and quasi-dynamic load are selected, loading rate levels are $10^{-1}, 10^{0}, 10^{1}, 10^{2}$, and $10^{3}$, respectively, and the loading rates are $0.5 \mathrm{~mm} / \mathrm{s}, 1.0 \mathrm{~mm} / \mathrm{s}$, $5.0 \mathrm{~mm} / \mathrm{s}, 10.0 \mathrm{~mm} / \mathrm{s}, 50.0 \mathrm{~mm} / \mathrm{s}, 100.0 \mathrm{~mm} / \mathrm{s}, 500.0 \mathrm{~mm} / \mathrm{s}$, and $1000 \mathrm{~mm} / \mathrm{s}$ for simulation.

Tests are to study the loading rates' effect on the anchorage strength with the loading rate as the only variable during the simulating process. Loading rates' influence on the anchoring 


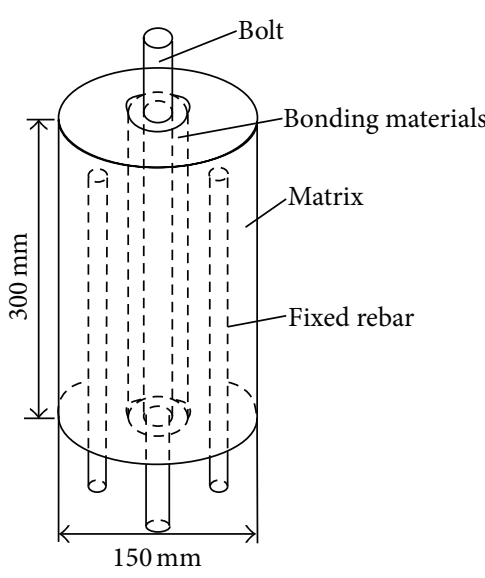

(a)

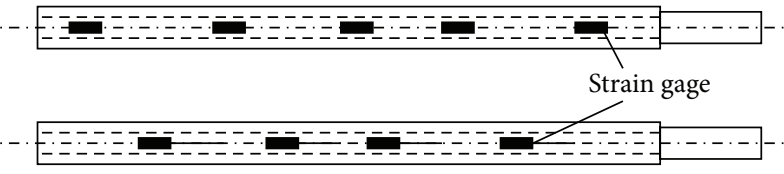

(b)

FIGURE 4: Structure model of anchorage body. (a) Integral structure. (b) Force anchor.

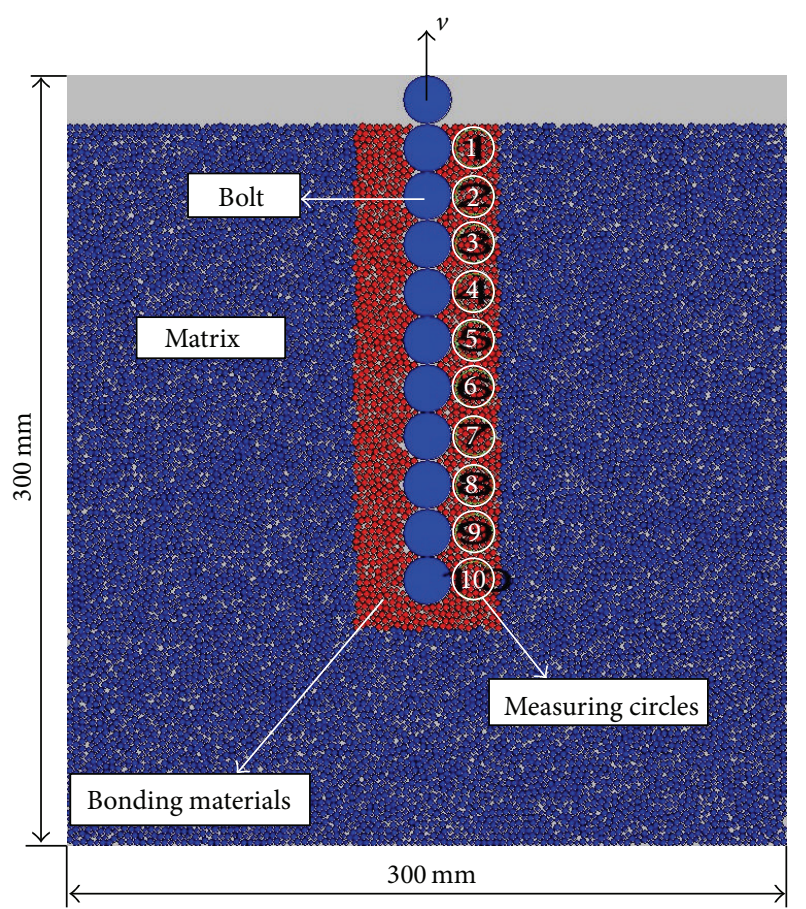

FIGURE 5: Micromechanical model of anchorage body's pull-out test.

TABLE 2: Rank classification of strain rates and loading rates [24].

\begin{tabular}{lcc}
\hline Loading cases & Strain rates $\left(\mathrm{s}^{-1}\right)$ & $\begin{array}{c}\text { Loading rates } \\
(\mathrm{mm} / \mathrm{s})\end{array}$ \\
\hline Creep & $<10^{-5}$ & $<10^{-3}$ \\
Static & $10^{-5} \sim 10^{-1}$ & $10^{-3} \sim 10^{1}$ \\
Quasi-dynamic & $10^{-1} \sim 10^{1}$ & $10^{1} \sim 10^{3}$ \\
Dynamic & $10^{1} \sim 10^{4}$ & $10^{3} \sim 10^{6}$ \\
Superdynamic & $>10^{4}$ & $>10^{6}$ \\
\hline
\end{tabular}

effect is illustrated through changes of failure strength, failure patterns, axial force, and shear stress.

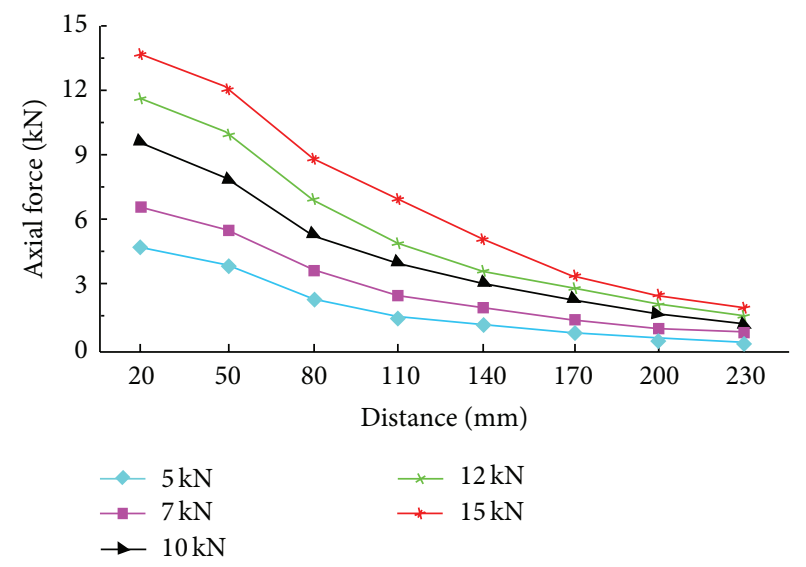

Figure 6: Axial force distribution.

\section{Results and Discussion}

4.1. Influence of Loading Rates on Axial Force Distribution. As is shown in Figure 6, axial force's distribution curves of bolts along the anchorage section could be got by pull-out tests of anchorage body. The distribution of axial force is nonuniform-on the pull-out side exists an obvious stress concentration, and it decreases gradually along the anchorage section. With the increase of pull-out force, the axial force of anchorage section increases gradually, and the largest force is on the pull-out side, while the amplitude of axial force's increase decreases along the anchorage section. Therefore, the scope of axial force's influence is certain, which means a length of effective anchorage exists.

The change of bolt axial force under different loading rates obtained from numerical simulation is shown in Figure 7, and its distribution is similar to the indoor test-the axial force decreases along the anchorage section. If $v<10 \mathrm{~mm} / \mathrm{s}$, its change on the influence of axial force can be ignored; if $10 \mathrm{~mm} / \mathrm{s}<v<100 \mathrm{~mm} / \mathrm{s}$, with the increase of loading rates, the axial force increases slowly between the pull-out side and 


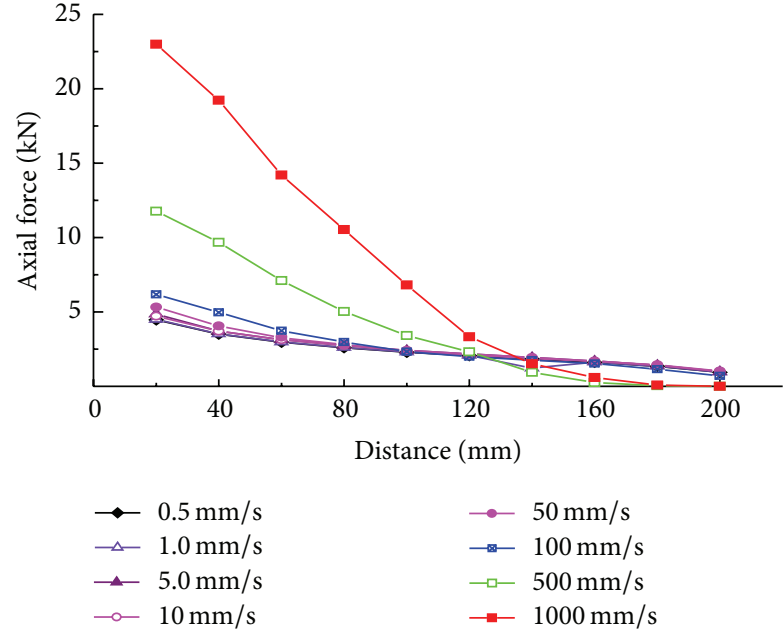

FIGURE 7: Changes of axial force under different loading rates.

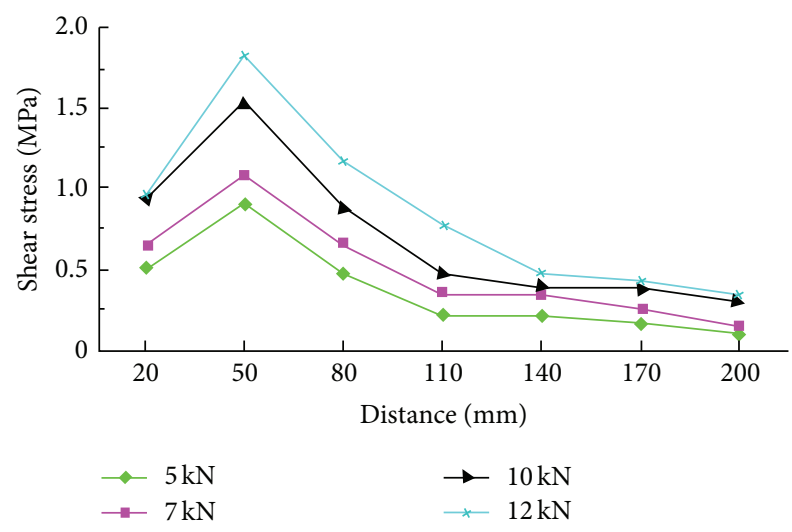

FIGURE 8: Shear stress distribution.

the middle, while it has no obvious changes between the middle and the bottom; if $v>100 \mathrm{~mm} / \mathrm{s}$, the axial force is much larger between the pull-out side and the middle than that of other loading rates $(v<100 \mathrm{~mm} / \mathrm{s})$ whereas axial force is almost zero along the distance between the middle and the bottom. Therefore, if the loading rate $v>100 \mathrm{~mm} / \mathrm{s}$, the larger the loading rates, the more steep the curve of axial force distribution, and that is prone to causing the impact damage of anchorage body.

4.2. Influence of Loading Rates on Interfacial Shear Stress Distribution. The curve of shear stress's distribution along the anchoring section is shown in Figure 8. The distribution of interfacial shear stress is nonuniform-shear stress is small at the orifice of the pull-out side but reaches peak after a certain distance away from the orifice and then drops rapidly. The shear stress under the middle of anchorage section changes a little, which means shear stress has a certain influencing scope as the axial force. With the increase of pull-out force, interfacial shear stress increases gradually, and the scope of its influence also increases, but its concentration remains mainly on the pull-out part of anchorage section.

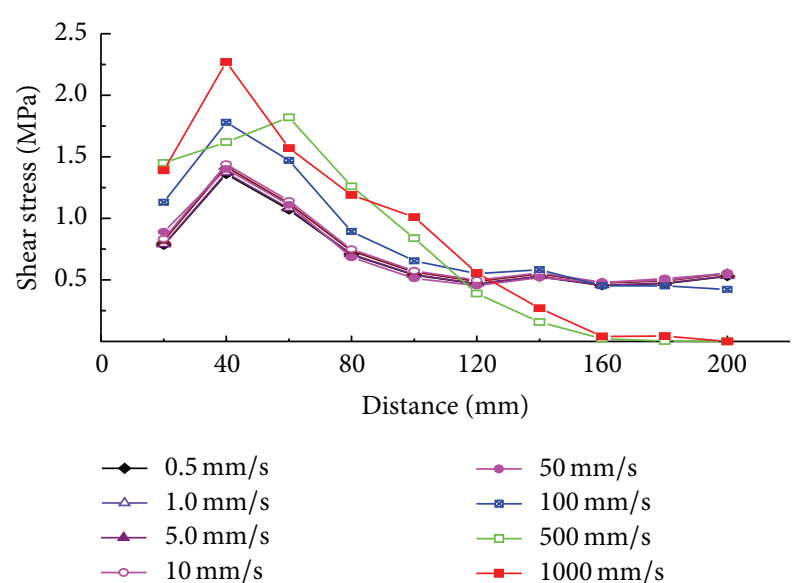

FIgURE 9: Changes of shear stress under different loading rates.

The change of interfacial shear stress under different loading rates is shown in Figure 9. When the loading rate $v$ is the same, the distribution of shear stress is nonuniformthe shear stress increases firstly and then decreases with the increase of anchorage length. If $v<10 \mathrm{~mm} / \mathrm{s}$, its change on the influence of shear stress can be ignored; if $10 \mathrm{~mm} / \mathrm{s}$ $<v<100 \mathrm{~mm} / \mathrm{s}$, with the increase of loading rates, the shear stress increases slowly; if $v>100 \mathrm{~mm} / \mathrm{s}$, the shear stress is larger between the pull-out part and the middle part of the anchorage section, while it is almost zero on the other part. Obviously, high loading rates cause apparent concentration of shear stress and its serious nonuniform distribution.

4.3. Influence of Loading Rates on the Pull-Out Force. According to pull-out tests of PFC scheme, different loading rates have been exerted at the end of bolt until the body's failure. Curves of pull-out load versus displacement and curves of failure load versus loading rates are shown in Figures 10 and 11 , respectively.

As is shown from the two figures, if the loading rate $v<$ $10 \mathrm{~mm} / \mathrm{s}$, the pull-out load is not affected obviously; if the loading rate $v>10 \mathrm{~mm} / \mathrm{s}$, the increase of loading rates will influence the pull-out load more and more obviously. The pull-out load of anchorage body's failure and loading rates show a linear correlation (the fitting curve: $y=64.10188+$ $0.27055 x)$.

4.4. Influence of Loading Rates on Failure Patterns. Final failure patterns of the model under different loading rates are shown in Figure 12, and we can find that if the loading rate $v<10 \mathrm{~mm} / \mathrm{s}$, the failure mode of the model is matrix cracking with a main crack, which crosses the bottom of the matrix; if the loading rate $v>10 \mathrm{~mm} / \mathrm{s}$, cracks grow in the upper part in addition to the main crossing crack; when the loading rate $v>100 \mathrm{~mm} / \mathrm{s}$, with the continuous increase of loading rates, cracks grow rapidly along the middle and upper parts of the bolt until the matrix cracking destruction evolves the bolt pull-out failure with large fracture zone. That means the higher the loading rate gets, the higher the anchorage body's broken degree will be. According to the influence degree 


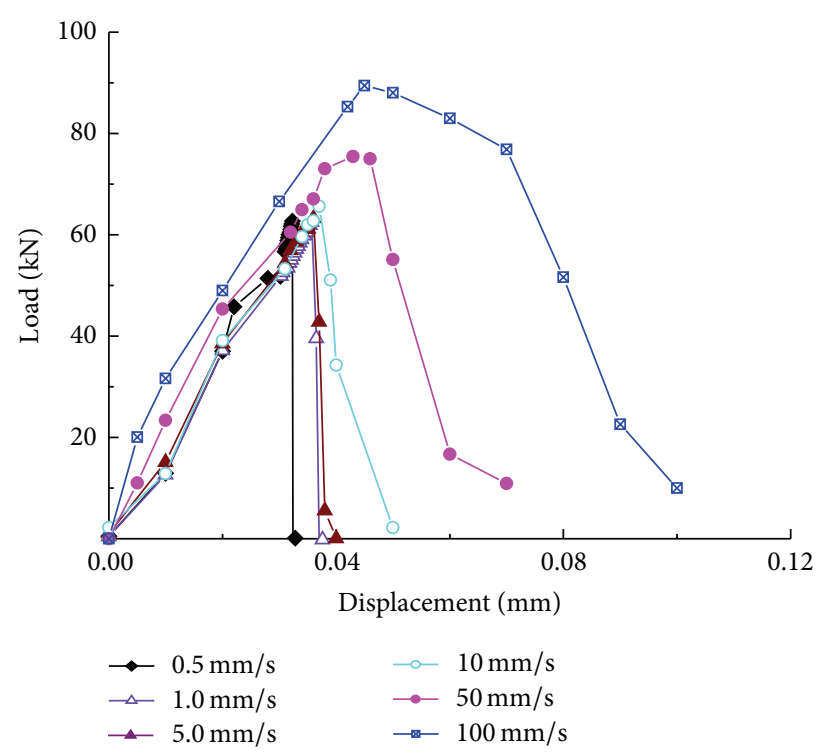

(a)

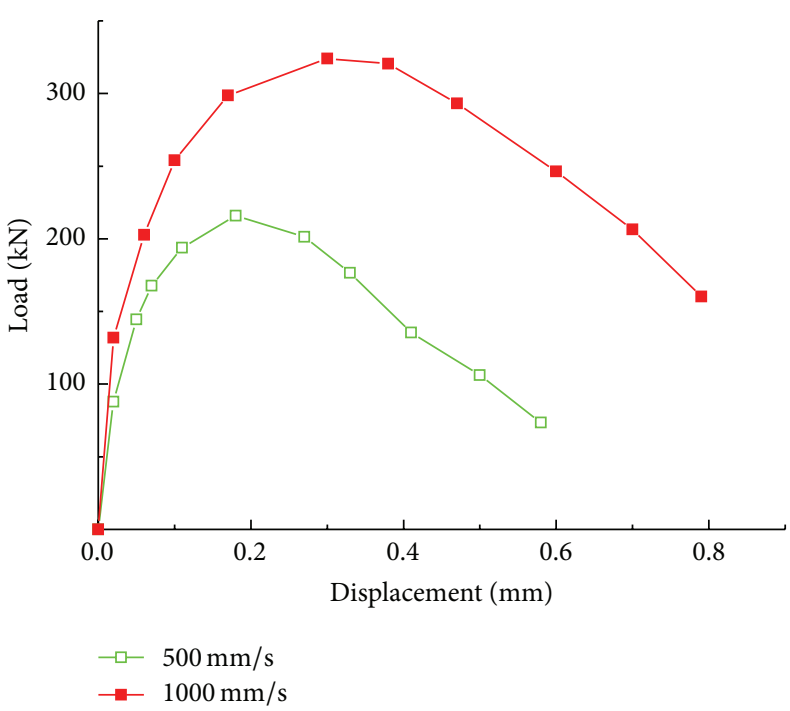

(b)

FIGURE 10: Load versus displacement. (a) $v \leq 100 \mathrm{~mm} / \mathrm{s}$; (b) $v>100 \mathrm{~mm} / \mathrm{s}$.

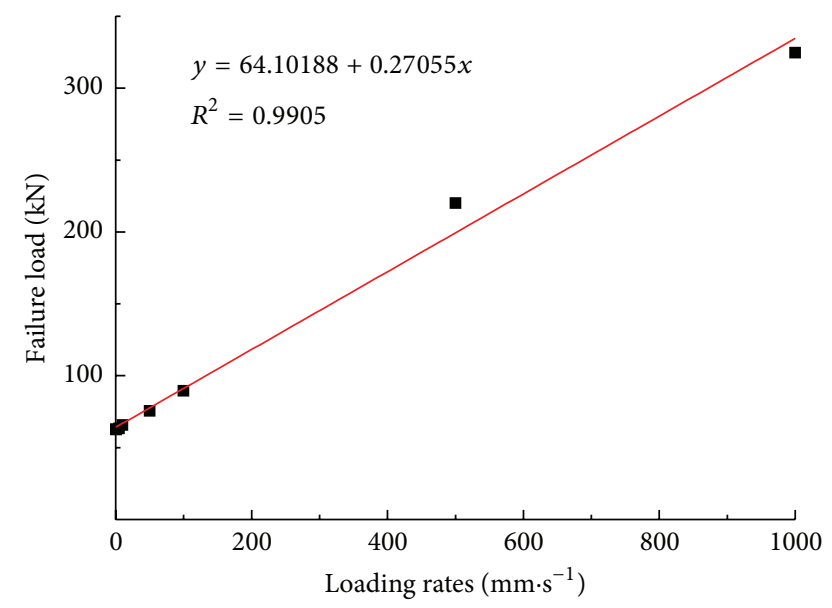

FIGURE 11: Failure load versus loading rate.

of loading rates, loading rates' scope can be divided into three conditions: soft scope $(v<10 \mathrm{~mm} / \mathrm{s})$, moderate scope $(10 \mathrm{~mm} / \mathrm{s}<v<100 \mathrm{~mm} / \mathrm{s})$, and strong scope $(v>100 \mathrm{~mm} / \mathrm{s})$.

The larger the loading rates are, the greater force the anchor stressed. Under high loading rates, the serious stress concentration along the upper anchorage section causes the broken of bonding materials and matrix around the bolt, which eventually leads to the bolt-out alone as the failure pattern of anchorage body.

\section{Conclusions}

Through the self-developed test apparatus for interfacial mechanics to study the distribution rule of axial force and interfacial stress of bolts in the anchorage body, $\mathrm{PFC}^{2 \mathrm{D}}$ software is employed to simulate pull-out tests of the anchorage body to research stress distribution under different loading rates. Some conclusions are as follows.

(1) In the pull-out test of anchorage body, the distribution of axial force is nonuniform. On the pull-out side exists an obvious stress concentration, and it decreases gradually along the anchorage section. With the increase of loading rates, axial force between the pull-out side and the middle of anchorage section increases, but, between the middle and the bottom, changes of axial force are not obvious. That causes the distribution curve of axial force to become more steep with the increase of loading rates, which means the axial force is greater in the upper anchorage section than that in the lower anchorage section.

(2) The distribution of interfacial shear stress is nonuniform. Shear stress is small at the orifice of the pull-out section but reaches peak after a certain distance away from the orifice and then drops rapidly. With the increase of loading rates, interfacial shear stress between the pull-out side and the middle of anchorage section shows a trend of increase, but changes are not obvious in the lower anchorage section. That causes serious stress concentration of the upper anchorage section and its nonuniform distribution.

(3) According to loading rates' impact on anchoring effect, the loading rates' scope can be divided into the soft scope $(v<10 \mathrm{~mm} / \mathrm{s})$, the moderate scope $(10 \mathrm{~mm} / \mathrm{s}<v<$ $100 \mathrm{~mm} / \mathrm{s})$, and the strong scope $(v>100 \mathrm{~mm} / \mathrm{s})$. Pull-out load will increase with the increase of loading rates, and they show a linear correlation. With the increase of loading rates, failure patterns will come into a trend of bolt pull-out only with wide broken zone due to serious stress concentration of the upper part of anchorage section. 


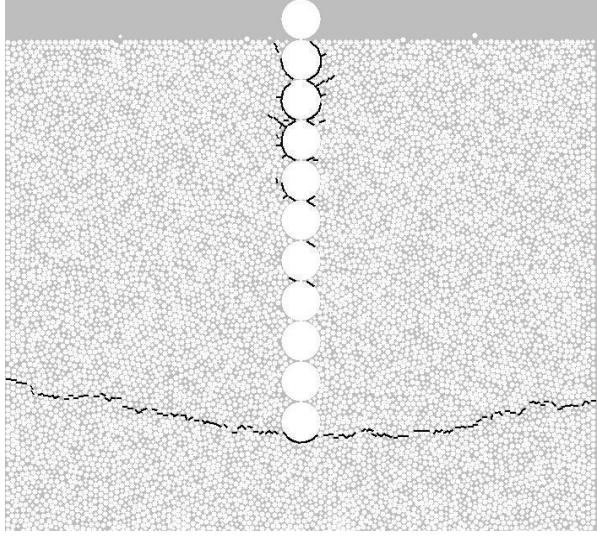

(a)

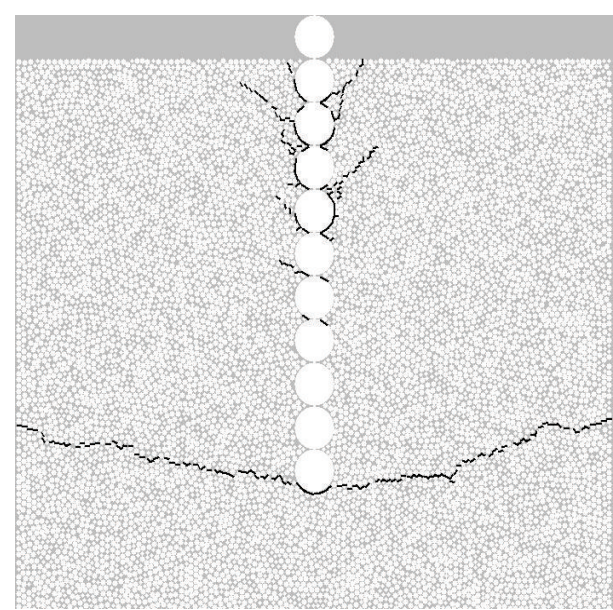

(c)

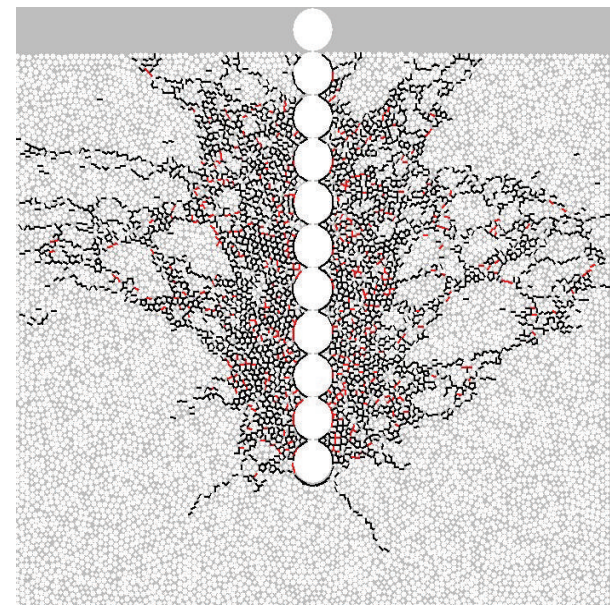

(e)

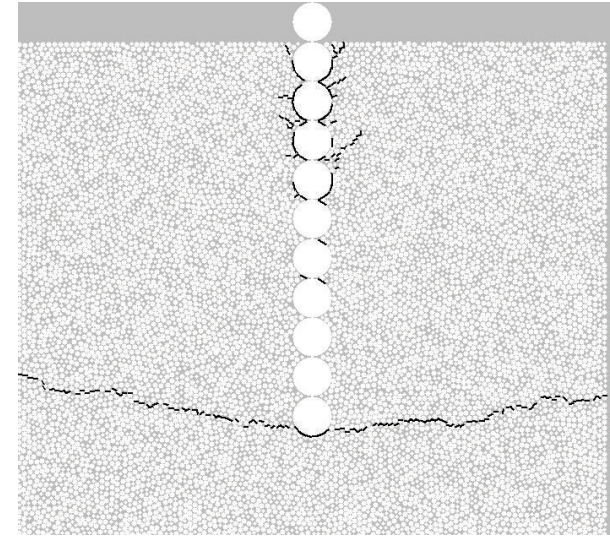

(b)

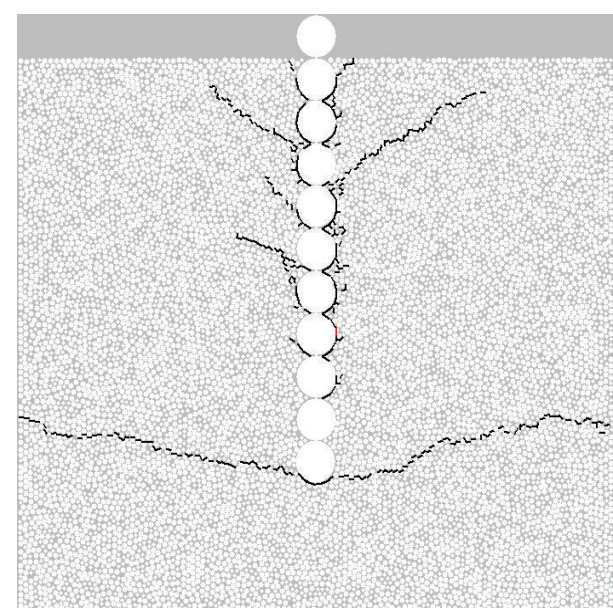

(d)

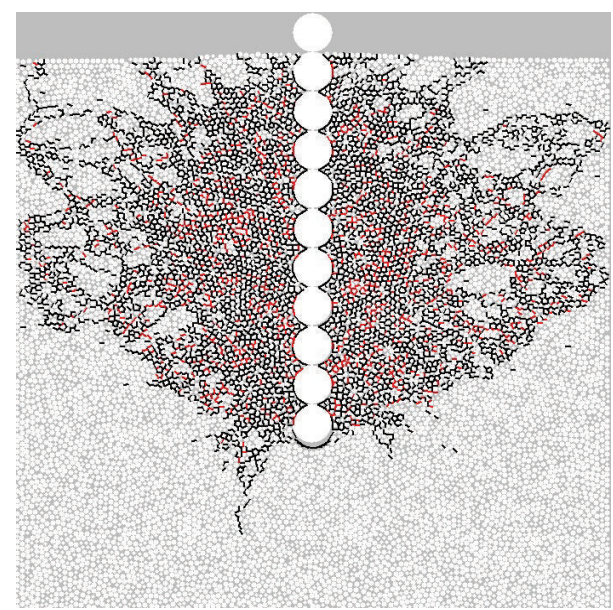

(f)

FIGURE 12: Failure patterns under different loading rates. (a) $5 \mathrm{~mm} / \mathrm{s}$; (b) $10 \mathrm{~mm} / \mathrm{s}$; (c) $50 \mathrm{~mm} / \mathrm{s}$; (d) $100 \mathrm{~mm} / \mathrm{s}$; (e) $500 \mathrm{~mm} / \mathrm{s}$; (f) $1000 \mathrm{~mm} / \mathrm{s}$. 


\section{Conflict of Interests}

The authors declare that there is no conflict of interests regarding the publication of this paper.

\section{Acknowledgments}

The work was supported by the Natural Science Foundation of China (no. 51474136), the open fund of State Key Laboratory of Mining Disaster Prevention and Control Co-founded by Shandong Province and the Ministry of Science and Technology (MDPC2013KF06), and the open fund of State Key Laboratory of Safe and Effective Coal Mining (JYBSYS2014202). The authors would like to thank them.

\section{References}

[1] Y.-L. Tan, Z. Zhang, and C.-L. Ma, "Rock burst disaster induced by mining abutment pressure," Disaster Advances, vol. 5, no. 4, pp. 378-382, 2012.

[2] Y. Tan, F. Li, Z. Hui et al., "Analysis on acoustic emission pattern for rock burst," Chinese Journal of Rock Mechanics and Engineering, vol. 19, no. 4, pp. 425-428, 2000.

[3] Z.-L. Li, L.-M. Dou, W. Cai et al., "Investigation and analysis of the rock burst mechanism induced within fault-pillars," International Journal of Rock Mechanics and Mining Sciences, vol. 70, pp. 192-200, 2014.

[4] L. Wang, Z.-L. Lu, and Q. Gao, "A numerical study of rock burst development and strain energy release," International Journal of Mining Science and Technology, vol. 22, no. 5, pp. 675-680, 2012.

[5] S.-H. Liu, "Nonlinear catastrophy model and chaotic dynamic mechanism of compound coal-rock unstable failure under coupled static-dynamic loading," Journal of the China Coal Society, vol. 39, no. 2, pp. 292-300, 2014.

[6] L.-M. Dou, W. Cai, S.-Y. Gong, R.-J. Han, and J. Liu, "Dynamic risk assessment of rock burst based on the technology of seismic computed tomography detection," Journal of the China Coal Society, vol. 39, no. 2, pp. 238-244, 2014.

[7] L.-M. Dou, T.-J. Chen, S.-Y. Gong, H. He, and S. Zhang, "Rockburst hazard determination by using computed tomography technology in deep workface," Safety Science, vol. 50, no. 4, pp. 736-740, 2012.

[8] H. Lan, Q.-X. Qi, J.-F. Pan et al., "Study status and prospects of mine pressure bumping control technology in China," Coal Science and Technology, vol. 39, no. 1, pp. 11-15, 2011.

[9] M.-S. Gao, L.-M. Dou, N. Zhang, K. Wang, and B.-S. Zheng, "Strong-soft-strong mechanical model for controlling roadway surrounding rock subjected to rock burst and its application," Rock and Soil Mechanics, vol. 29, no. 2, pp. 359-364, 2008.

[10] X.-F. Lü and Y.-S. Pan, "Simulation and numerical analysis of impact failure law of coal roadway under rigid-flexible energy absorbing support," Chinese Journal of Geotechnical Engineering, vol. 34, no. 3, pp. 477-482, 2012.

[11] W.-J. Wang, G. Peng, and J. Huang, "Research on high-strength coupling support technology of high stress extremely soft rock roadway," Journal of the China Coal Society, vol. 36, no. 2, pp. 223-228, 2011.

[12] M.-C. He, J. Wang, X.-M. Sun, and X.-J. Yang, "Mechanics characteristics and applications of prevention and control rock bursts of the negative poisson's ratio effect anchor," Journal of the China Coal Society, vol. 39, no. 2, pp. 214-221, 2014.
[13] L. V. Rabcewicz, “The new Austrian tunneling method," Water Power, vol. 17, no. 1, pp. 511-515, 1964.

[14] A.-H. Lu, J.-H. Xu, and H.-S. Liu, "Effect of a preload force on anchor system frequency," International Journal of Mining Science and Technology, vol. 23, no. 1, pp. 135-138, 2013.

[15] Y.-S. Kang, Q.-S. Liu, G.-Q. Gong, and H.-C. Wang, "Application of a combined support system to the weak floor reinforcement in deep underground coal mine," International Journal of Rock Mechanics and Mining Sciences, vol. 71, pp. 143-150, 2014.

[16] T.-B. Zhao, Y.-C. Yin, Y.-L. Tan, and Y. Qiu, "Mechanical test of bolt interface and microscopic simulation of transfer law for shear stress," Journal of Mining and Safety Engineering, vol. 28, no. 2, pp. 220-224, 2011.

[17] T.-B. Zhao, Y.-L. Tan, S.-S. Liu, and Y.-X. Xiao, "Analysis of rheological properties and control mechanism of anchored rock," Rock and Soil Mechanics, vol. 33, no. 6, pp. 1730-1734, 2012.

[18] S. H. E. Phillips, Factors Affecting the Design of Anchorages in Rock, Cementation Research, London, UK, 1970.

[19] M.-S. Wang, H.-R. He, and Y.-T. Zheng, "Mechanical model of full grouting bolt and its application," Metal Mine, no. 4, pp. 2124, 1983.

[20] C.-A. You, M. Gao, L.-M. Zhang, Y.-B. Zhan, and J.-H. Wang, "Experimental research on stress distribution in anchorage body," Rock and Soil Mechanics, vol. 25, supplement 1, pp. 6366, 2004.

[21] T.-B. Zhao, Creep Properties Test and Anchorage Control TimeDependency of Surrounding Rock in Deep Mine, Shandong University of Science and Technology, Qingdao, China, 2009.

[22] Y.-C. Yin, T.-B. Zhao, Y.-L. Tan, and Z. Zhang, "Research of stress distribution evolution law and influencing factors," Journal of Mining and Safety Engineering, vol. 30, no. 5, pp. 712716, 2013.

[23] D. O. Potyondy and P. A. Cundall, "A bonded-particle model for rock," International Journal of Rock Mechanics \& Mining Sciences, vol. 41, no. 8, pp. 1329-1364, 2004.

[24] M.-R. Shen and J.-F. Chen, Rock Mechanics, Tongji University Press, Shanghai, China, 2006. 

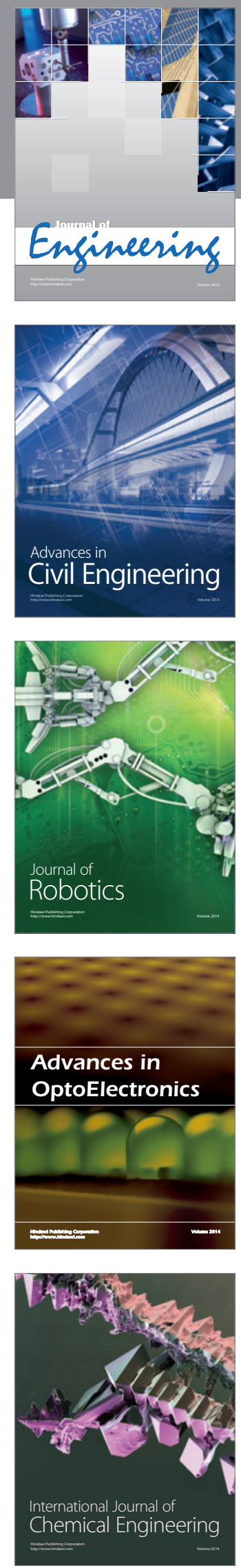

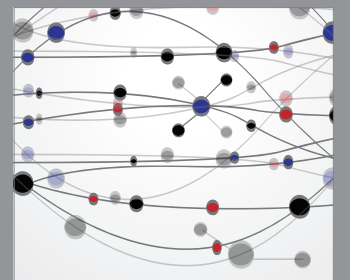

The Scientific World Journal
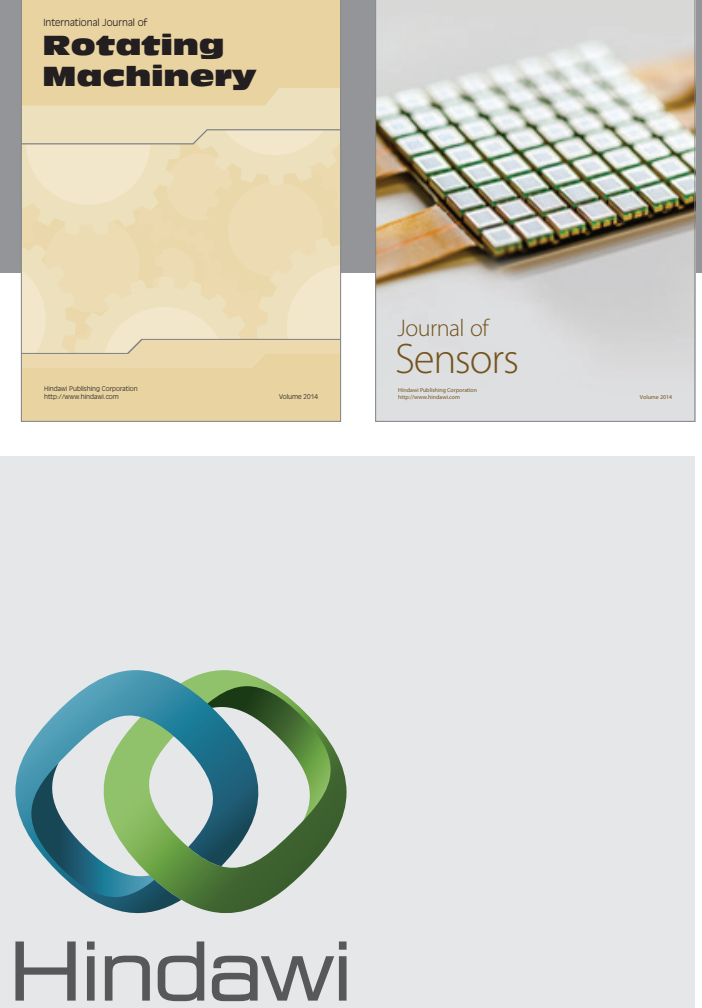

Submit your manuscripts at http://www.hindawi.com
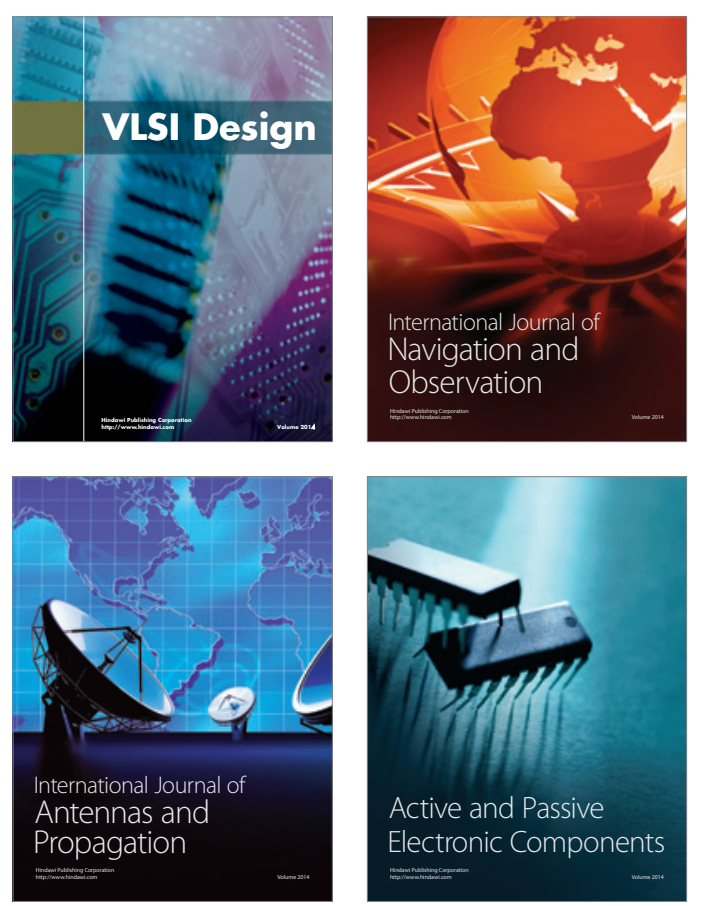
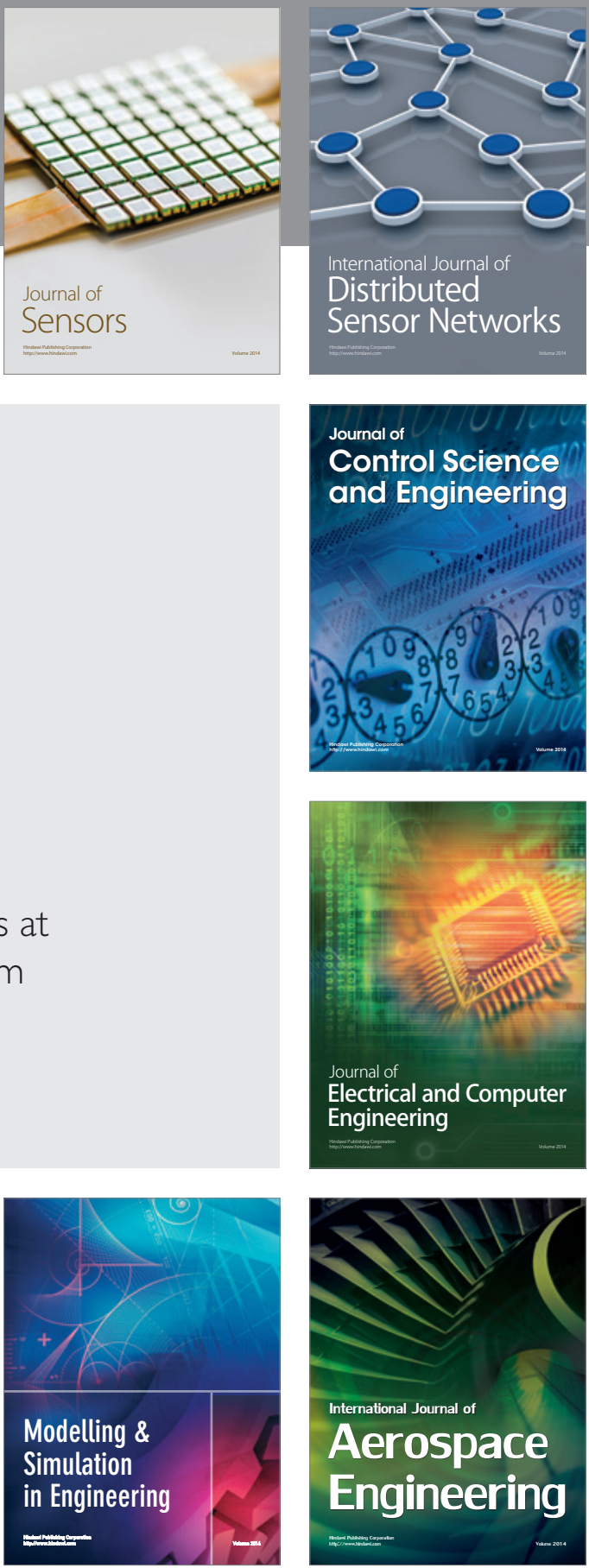

Journal of

Control Science

and Engineering
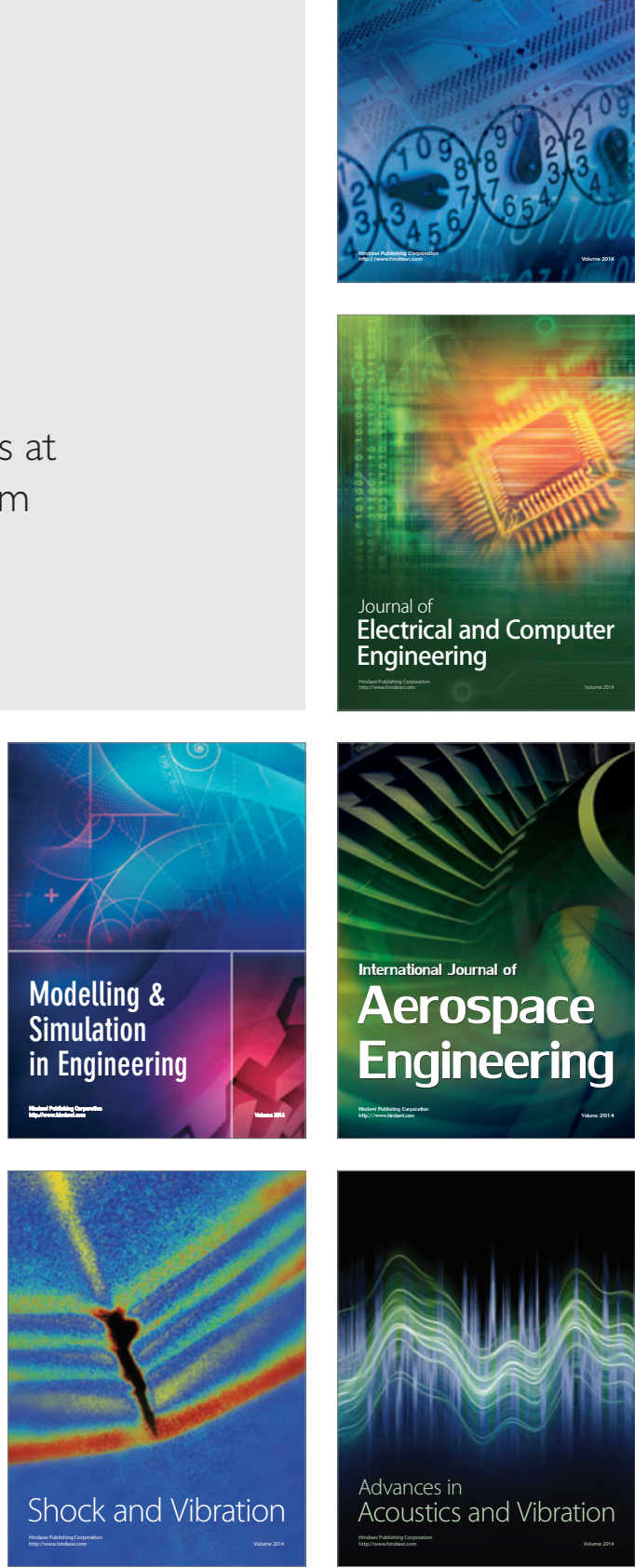